\title{
Identification of protein profiles of Escherichia coli, Staphylococcus aureus and their corresponding phages
}

\author{
Ayman, A. Elshayeb ${ }^{1}$; Sanaa O. Yagoub ${ }^{2}$; Ashraf S. Yousif ; Eshtiyag A. \\ Abedalkareem ${ }^{3}$; Salma M. El hag ${ }^{3}$; and Atif A. Elagib ${ }^{3}$ \\ ${ }^{1}$ Department of Microbiology and Molecularbiology-School of Biotechnology-Faculty of \\ Science and Technology-Alneelain University-Khartoum-Sudan \\ ${ }^{2}$ Faculty of Pharmacology, Qassim University, Saudi Arabia. \\ ${ }^{3}$ Department of Immunology and Biotechnology-Tropical Medicine Research Institute \\ (TMRI)-National Centre for Research (NCR)-Khartoum-Sudan
}

\begin{abstract}
The present study was carried out for the assessment and detecting of the Escherichia coli and Staphylococcus aureus bacteriophages and their bacterial host's proteins includes visual inspection and comparison of their molecular weight mass. Systematic methods that use microorganisms (viruses and bacteria) to test samples from the local sewage water have been developed but require some change in the classical culturing of the organism to detect it easily by naked eye through the changes in selective media. We have developed a Sodium Dodecyl Sulphate Ploy Acrylamide Gel Electrophoresis (SDS PAGE) assay for bacteriophage samples preparation that allows the rapid detection of proteins bands of these viruses by using freeze drying technique. We found that the protein profiles of $E$. coli bacteriophage showed three major bands with molecular weight mass of 47,35 and 16 kilo Dalton and 34 and $20 \mathrm{kDa}$ for S. aureus phage, the band of 35 $\mathrm{kDa}$ was the common shared peak between the phage and the bacterial host due to the bacteriophage lytic cycle. The method is suitable for use with both the bacteriophages and their bacterial hosts. The assay is rapid, sensitive, and inexpensive; requires only small sample volumes; and can be automated.
\end{abstract}

Keywords: Bacteriophage/ Escherichia coli/ / Protein profile/ Stabilisation Station staphylococcus aureus/.

\section{INTRODUCTION}

Each kind of bacteria has its own phage/s, which can be isolated wherever that particular bacterium grows from sewage, faeces, soil, even ocean depths and hot springs. Phages are basically nucleic acid with a protein coat around them, and once the nucleic acid is injected in the bacteria, then they very often take over the chemistry of the bacteria, making the bacteria into a factory to make more phage particles, and they have enzymes that will dissolve the bacteria from the inside out, so that they can then release the freshly made bacterial viruses. So they're almost like a biological hypodermic needle that plug themselves into a bacterium and then take over the machinery of the bacteria itself. And of course that mechanism lends to what we call exponential growth, so it means that if you infect bacterial culture with one viral particle, it will then make 10 , or 100 , or 1000 copies of it in the bacteria. They then will go on and infect more bacteria and it grows exponentially that way, (Dressler, et al, 1972). Microbiological methods have the advantage of providing information about the sensitivity of a culture but do not discern phage species (Labrie and Moineau, 1999). On the other hand, molecular techniques such as Sodium Dodecyl Sulphate Ploy Acrylamide Gel Electrophoresis (SDS PAGE) can determine the nature of the phage proteins' molecular weights but do not detect active lytic cycles. The current molecular systems also have a good sensitivity and do not need multiple reactions to identify the distinct species. SDS PAGE is fundamentally designed to detect protein molecules also extensively used as a detection and identification tool for viruses and bacteria in different environments (Zimmer, et al, 2002). The SDS PAGE method has been adapted for the detection of Escherichia coli and Staphylococcus aureus bacteriophages in sewage water. This gel system uses the method described by (Laemmli 1970). In this technique, the protein sample was denatured and coated with detergent by heating in the presence of SDS and a reducing agent. The SDS coating gives the protein a high net negative charge that is proportional to the length of the polypeptide chain. The sample is loaded on a polyacrylamide gel and high voltage is applied, causing the protein 
components to migrate toward the positive electrode (anode). Since all of the proteins have a net negative charge that is in proportion to their size, the proteins are separated solely based on their molecular mass, a result of sieving effect of the gel matrix. The molecular mass of the protein can be estimated by comparing the mobility of a band with protein standards, (Ding, 2001).

\section{MATERIALS AND METHODS}

Harvest of samples for protein profile: Samples were harvested from different types of media to detect the existence of the bacteria and bacteriophages' proteins, equal volumes of the centrifugation resulting precipitation was taken to the freeze dryer, the final samples' weight was the preparation of the Sodium Dodecyl Sulphate Poly

Acrylamide Gel Electrophoresis.

Preparation of the bacteria antigens: According to (Ding, 2001), Bacteria were incubated at $30^{\circ} \mathrm{C}$ in nutrient broth with SM buffer (for 1 litre: $\mathrm{NaCl} 5.8 \mathrm{~g}$, $\mathrm{MgSO}_{4} .7 \mathrm{H}_{2} \mathrm{O} 2.0 \mathrm{~g}, 2 \%$ gelatine solution , Tris $\mathrm{HCl}$ $1 \mathrm{M}$ ( $\mathrm{pH} 7.5) 50 \mathrm{ml}$. Distil water), for $2-3$ days, then cells were removed from media by centrifugation for 3 minutes at $15,000 \mathrm{rpm}$. The supernatants were discards and the precipitations were filtered by Millipore filter with a pore size of $0.45 \mu \mathrm{m}$ and stored at $-50^{\circ} \mathrm{C}$. afterward, the samples were crushed by glass rod and homogenised in sterile distilled water in volume 15 times less than their initial volume.

Preparation of the bacteriophage antigens: E. coli and $\mathrm{S}$. aureus bacteriophages were prepared by inoculating the bacteria in semi solid medium tryptone soy agar- (TSA). Then single plaques were picked and placed into $0.45 \mathrm{ml}$ of liquid medium tryptone soy broth - (TSB), after 4 hours of incubation at $4^{\circ} \mathrm{C}$, the phage - containing solution was filtered with filter paper with a pore size of $0.45 \mu \mathrm{m}$ sterilised and used for a second round of purification.

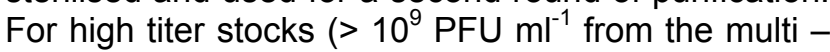
tube Ringer's solution quarter strength) liquid cultures of $\mathrm{E}$. coli and S. aureus were used, $0.1 \mathrm{ml}$ of phage was added to $0.2 \mathrm{ml}$ of bacteria and incubated for 4 hours at $4^{\circ} \mathrm{C}$. Chloroform $(3 \% \mathrm{v} / \mathrm{v})$ was used to lyse the bacterial cells, and cellular debris was subsequently removed by centrifugation for 5 minutes at $5000 \mathrm{rpm}$. The supernatant was collected, chloroform added again and centrifuged a second time. The bacteriophage proteins were then pelted by centrifugation for 30 minutes at $5000 \mathrm{rpm}$. The supernatant was discarded and the pellets were resuspended in $150 \mu \mathrm{l}$ fresh SM buffer and stored at $4^{\circ} \mathrm{C}$, afterward, the samples were freeze dried and homogenised in sterile distilled water in volume 15 times less than their initial volume.

Sodium dodecyl sulphate polyacrylamide gel electrophoresis (SDSP-AGE):

Homogeneous reducing one-dimensional sodium dodecyl sulfate-polyacrylamide gel electrophoresis (1D SDS PAGE) at $12.5 \%$ (wt/vol) was carried out as described by (Laemmli, 1970) in minigels (Mini-V 8.10) in GIBCO BRLVertical Gel Electrophoresis Apparatus (Life Technologies ${ }^{\mathrm{TM}}$ ). Bacteria and Bacteriophage antigens were separated at $100 \mathrm{~V}$ (constant) for 1-2 hours. Prestained molecular weight standards (SDSH6, Sigma) were run simultaneously on the same gel. After the run completed gels removed and stained with Comassie brilliant blue (CBB) stain which turned the entire gel blue and the gel destained by destaining solution. After destaining, the blue protein bands appeared against a clear background. The gel was photographed with digital camera and the protein bands analysed by UN-SCAN-IT gel software and Image J $136 \mathrm{~b}$ by Wayne Rasband, to determine the molecular weight of the samples in contrast with molecular weight of standards.

\section{RESULTS AND DISCUSSION}

The plaques of the E. coli bacteriophage occurred in colourless on the selective media and take no colour when stained with Gram stain figure (1). 
Am. J. Biotechnol. Mol. Sci., 2011, 1(2): 39-44

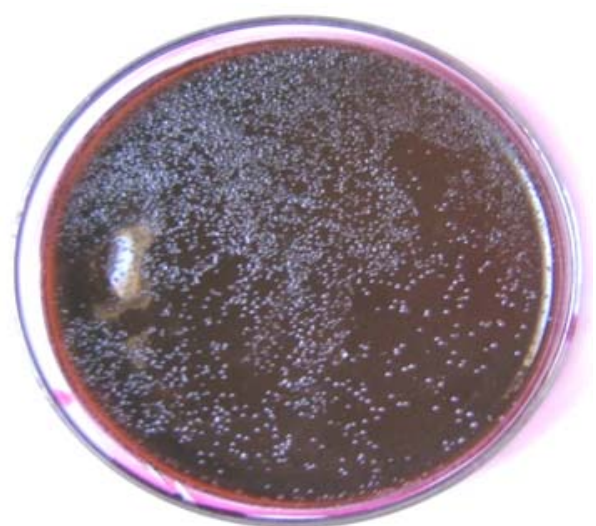

Fig (1): E. coli Bacteriophage affection on solid media (Eosin Methylene Blue)

Samples were harvested from different types of media Figure (2) to detect the existence of the bacteriophages' proteins, equal volumes of the centrifugation resulting precipitation was taken to the freeze dryer, the final samples' weight was the preparation of the (SDS PAGE).

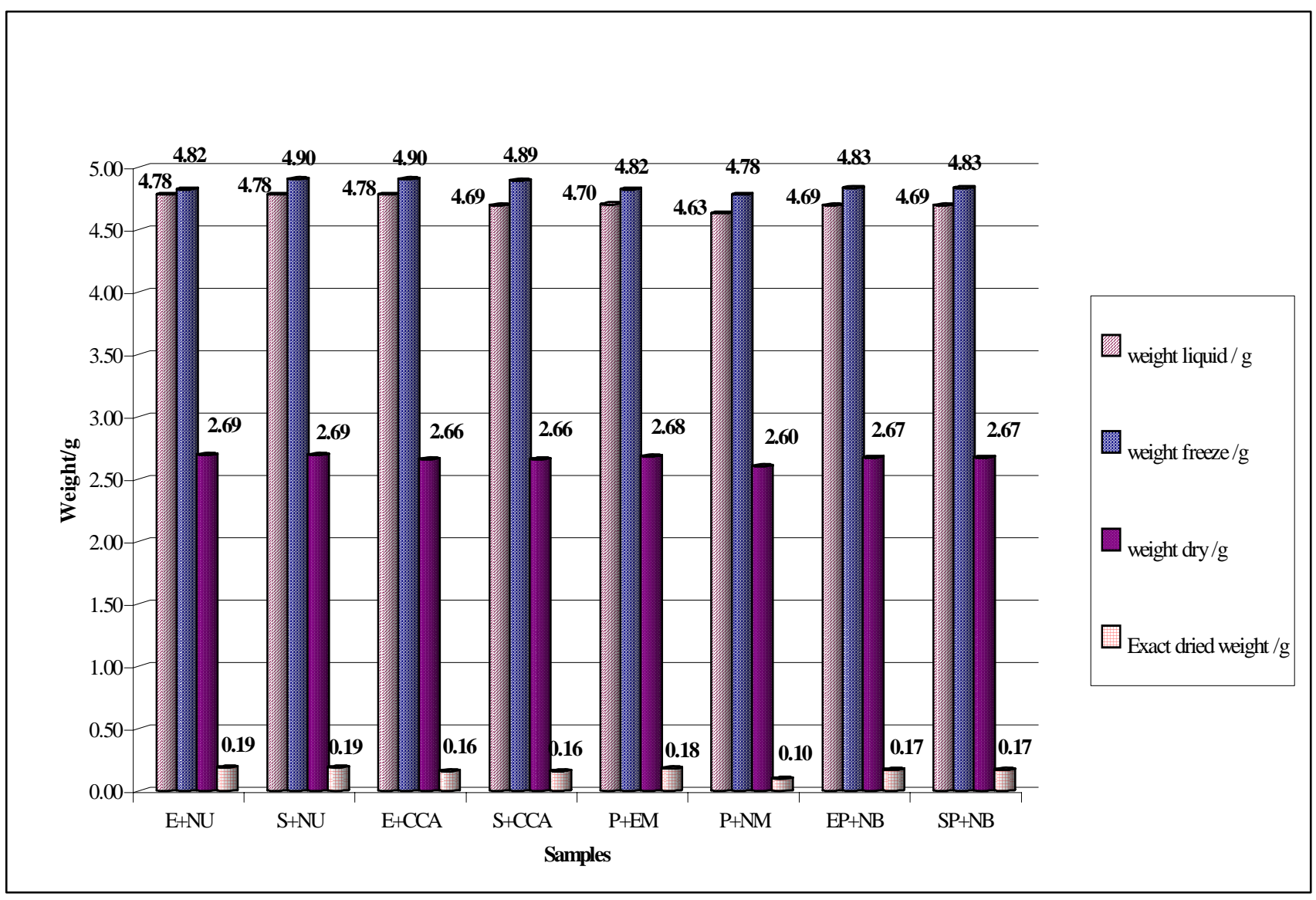

Fig 2.: Samples harvested for freeze drying 
The comparison of the dry weight ratio in the freeze samples and the liquid ones showed small differences of the sample size Figure (3)),

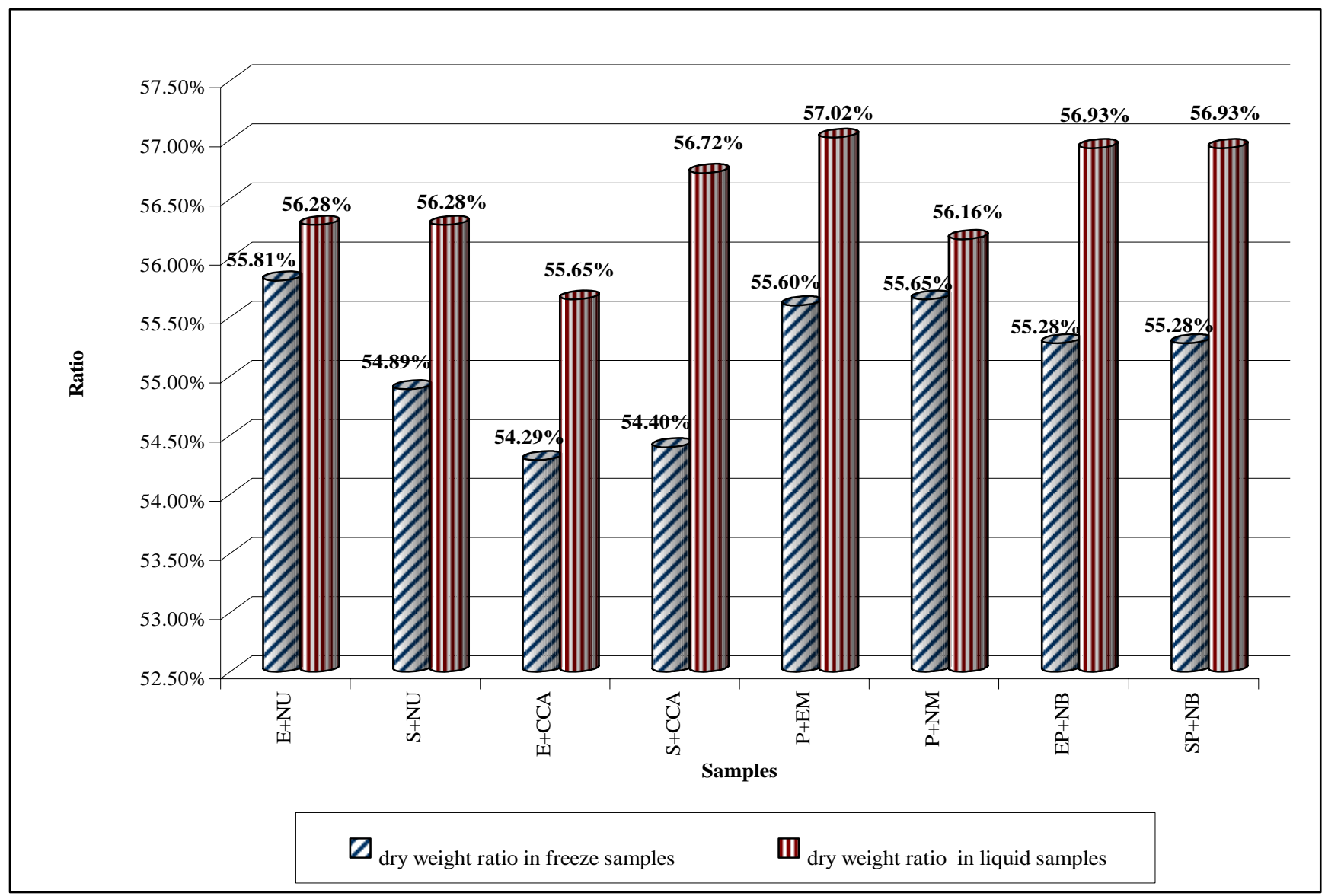

Fig 3: Ratio of dry weight samples

The purpose from freeze drying is to avoid contamination of the laboratory equipments and to ensure that all the phage were killed in this step beside it can replace the step of ultra centrifugation, meanwhile, the dry samples can be kept in room temperature in with silica gel granules. 


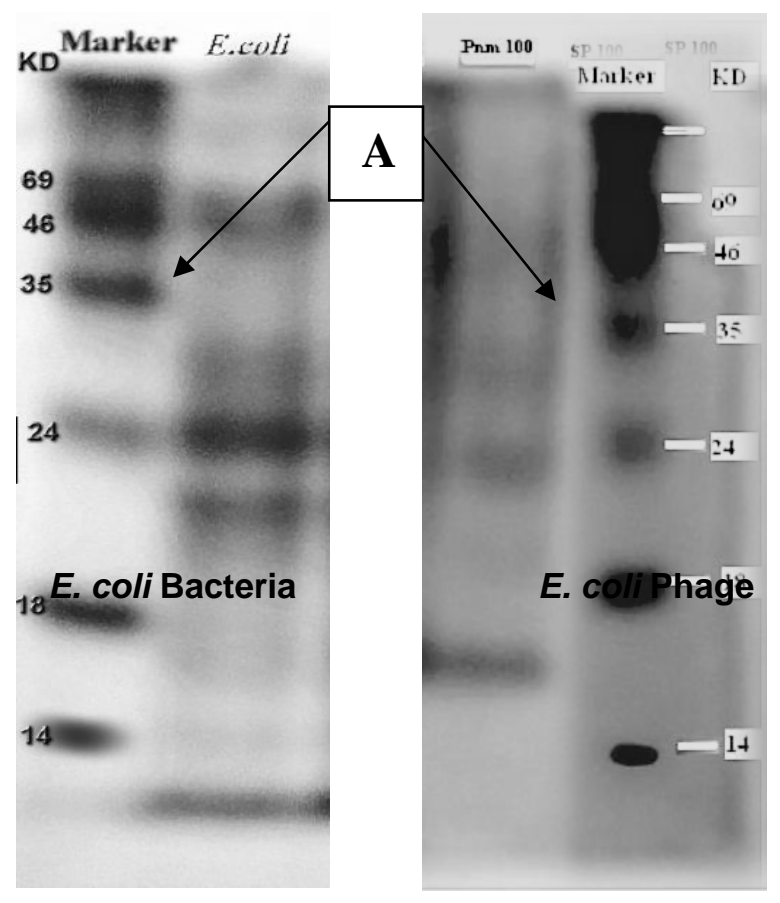

Fig (4): E. coli bacteria \& Phage protein profile

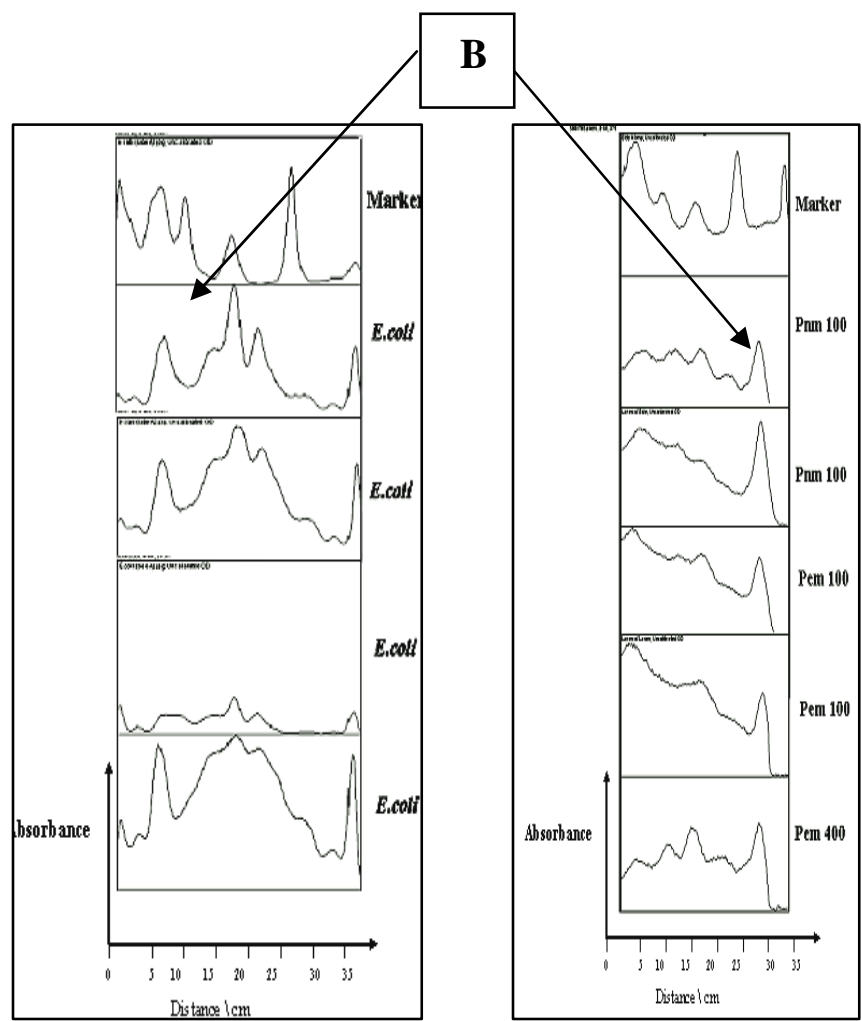

Fig (5): E. coli bacteria \& Phage protein profile analysis

A: Band of $35 \mathrm{kD}$. B: Common shared peak of band $35 \mathrm{kD}$.

In order to estimate the molecular weights of the proteins in the samples, the migration of each band was compared to the migration of the protein standards of known molecular weights in the molecular ladder. SDS PAGE analysis of purified bacteriophages showed three major bands, with molecular masses of 47, 34 and $16 \mathrm{kDa}$ Figure (4), this range nearly agreed (Barbian and Minnick, 2000) who found that SDSPAGE analysis of purified bacteriophage-like particle from Bartonella Bacilliformis showed three major proteins with apparent molecular masses of 32, 34 and $36 \mathrm{kDa}$; values that closely correspond to proteins found in $B$. henselae BLPs. The results also agreed (Zimmer, et al, 2002) who found the major capsid component results in size from 47.7 to $34.3 \mathrm{KDa}$ resembles $43.3 \%$ of total phage protein and the tail protein corresponds to $12.7 \%$ with an apparent size of $27 \mathrm{kDa}$. The predicted size was $22.5 \mathrm{kDa}$. Tailed bacteriophages frequently have a pair of overlapping ORFs between the major tail protein gene and the tail length tape measure gene that are expressed by a translational frameshift (Juhala, et al, 2000). This seems to be the case for ORF12 and ORF12.1, resembling the situation in phage (Levin, et al,1993).
The length of the phage tail is thought to be determined by a ruler mechanism, dependent on the size of the so-called tape measure protein (Katsura, 1987).

The protein profiles of the bacteria showed nine major bands Figure (4), the analysis and estimations of the open reading frames indicate that nearly half of the encoded proteins have to be assigned to proteins with unknown function (Mueller, 2000). However, the gel electrophoresis of the detected protein showed nine strong bands; six of them lies in the range of the marker molecular weight mass Figure (4), ( Ucan, et al, 2005) reported that the SDS-PAGE of whole-cell protein extracts of $E$. coli strains produced patterns containing 26 to 35 discrete bands with molecular weights of $6500-200,000 \mathrm{kDa}$.

The protein profiles analysed data by the ImageJ programme showed similar peaks of bacteriophages and bacteria bands Figures (5), this is related to the lytic cycle of the bacteriophages and their phenomenon in utilising the bacterial proteins during their multiplication inside the host. We found that the band of $35 \mathrm{kDa}$ was the common shared peak 
between the phage and the bacterial host, (Zimmer, et al, 2000) reported that this molecular weight mass 47.7 to $34.3 \mathrm{kDa}$ formed the capsid head and the coil resembles the total protein while the molecular weight mass of $22.5 \mathrm{kDa}$ formed the tail proteins.

\section{ACKNOWLEDGMENT}

We acknowledge with gratitude the assistance received from all the laboratory staff at School of life Sciences, School of Biotechnology-Faculty of Science and Technology-Alneelain University and Department of Immunology and Biotechnology-Tropical Medicine Research Institute.

\section{REFERENCES}

Barbian, K.D. and M.F. Minnick, (2000). A bacteriophagelike particle from Bartonella bacilliforms. American Journal of Microbiology 146: 599 - 609.

D'Herelle, F. (1917). Sur un microbe invisible antagoniste des bac. dysentËriques. Cr. r. Acad. Sci. Paris 165:373.

D'Herelle, F., F. W. Twort, J. Bordet and A. Gratia, (1922). Discussion on the Bacteriophage (Bacteriolysin). from the Ninetieth Annual Meeting of the British Medical Association, Glasgow, July, 1922. Published in the British Medical Journal 2:289-297, and reproduced in G. Stent, Papers on Bacterial Viruses, second edition, Little, Brown and Co., Boston, 1965.

Ding H., (2001). Functional characterization of Pura in vivo and in vitro - Pura knock-out mice and Pura DNA unwinding activity. PhD dissertation. Ludwig Maximilians University Munich, Germany.

Dressler D., J. Wolfson and M. Magazin,(1972) Initiation and reinitiation of DNA synthesis during replication of bacteriophage T7. Proc Natl Acad Sci USA 69: 9981002
Harrigan W.F. and M. E McCance (1993). Laboratory methods in food dairy microbiology. Academic Press. Harcourt Brace and Company Publishers. London U.K.

Juhala, R. J., M. E. Ford, R. L. Duda, A. Youlton, G. F. Hatfull, and R. W. Hendrix. (2000). Genomic sequences of bacteriophages HK97 and HK022: pervasive genetic mosaicism in the lambdoid bacteriophages. J. Mol. Biol. 299:27-51.

Katsura, I. 1987. Determination of bacteriophage lambda tail length by a protein ruler. Nature 327:73-75.

Labrie S. and S. Moineau, (1999). Multiplex PCR for Detection and Identification of Lactococcal Bacteriophages. Applied and Environmental Microbiology Vol. 66, No. 3: 987-994

Laemmli, U.K. (1970) Cleavage of structural proteins during the assembly of the head of bacteriophage T4, Nature, 227: 680-685.

Levin, M. E., R. W. Hendrix, and S. R. Casjens. 1993. A programmed translational frameshift is required for the synthesis of a bacteriophage lambda tail assembly protein. J. Mol. Biol. 234:124-139.

Mueller, M., (2000). Persistent bacterial infections: Identification of immunogenic structure of Borrelia burgdorferi sensu lato and Chlamydophila pnemoniae by phage surface display. PhD dissertation. Konstanz Univeristy Germany.

Twort, F. W. (1915). An investigation on the nature of ultramicroscopic viruses. Lancet 1915 II:1241.

Ucan, U.S., L. Acik, A. Celebl, O. Erganis and E. Arslan, (2005). Plasmids and proteins patterns of Escherichia coli isolated from bovine mastitis in Konya, Turkey. Turk Vet Anim Sci. 29: 475 - 480.

Zimmer M., S. Scherer, and M. J. Loessner, (2002 Genomic Analysis of Clostridium perfringens Bacteriophage $\$ 3626$, Which Integrates into guaA and Possibly Affects Sporulation. Journal of Bacteriology,. Vol. 184, No. 16: 4359-4368 